Acta Universitatis Wratislaviensis No 3920

Anglica Wratislaviensia LVII, Wrocław 2019

DOI: 10.19195/0301-7966.57.4

\author{
Harmony Ki Tak Law \\ ORCID: 0000-0003-3464-8780 \\ York University \\ harmo62@yorku.ca, harmonyktlaw@gmail.com

\section{Activism and Assimilation: The Political Memoirs of Olivia Chow and Adrienne Clarkson}

\begin{abstract}
While the history of Chinese settlement in Canada is touted as an example of perseverance despite racist opposition and of socio-economic success under Canada's immigration and multiculturalism policies, it is important to remember the very active role that Chinese Canadians played in their own trajectory. Throughout its history, the Chinese Canadian community has engaged in civic and political activism, on the one hand, and the promotion of positive stereotypes associated with assimilation into Euro-Canadian society on the other. Both of these approaches can be seen in the political memoirs of two prominent Chinese Canadian women: My Journey by Olivia Chow, a Member of Parliament who focused her career on a plethora of social justice initiatives; and Heart Matters by Adrienne Clarkson, a former Governor General who deemphasizes her Chinese heritage in order to mould herself into the ideal Canadian citizen. Despite these clear differences in political ideology and personal identity, both Chow and Clarkson's memoirs reveal the ways in which Chinese Canadians can not only claim full belonging as Canadian citizens, but also interrogate systemic forms of racism and inequality.
\end{abstract}

Keywords: Chinese Canadian, life writing, political memoir, social justice, political activism, ethnonationalism, Canadian multiculturalism, Canadian culture, Canadian identity

For a concrete example of how Canadian racial policy has evolved since Confederation in 1867, there appears to be no better case than the story of Chinese Canadians. Chinese migrant workers first came to Canada in the mid-19th century, and were heavily involved in the development of British Columbia in particular (Report 95). However, because Chinese immigrants were perceived as economic and cultural threats to the creation of an idealized white Canadian nation-state, the federal government moved to restrict their numbers, barring Chinese immigration from 1923 to 1947. Yet, after the Second World War, as Canada tried to reinvent itself as a progressive and peacekeeping nation, racial restrictions on immigration were gradually reduced: the exclusionary immigration policy was lifted; a points 
system was introduced in 1967 that would supposedly grade applicants for immigration according to their educational and professional merits; and an official multiculturalism policy was declared by Canada's federal government in 1970 . This new approach to racial and ethnocultural relations in Canada, along with economic booms in Hong Kong, Taiwan, and the People's Republic of China, allowed Chinese immigrants to arrive in greater numbers and succeed economically and socially in ways that their predecessors could not; Peter Li notes, for instance, that by 1991 "approximately 58 per cent of native-born Chinese-Canadians ... were in managerial, professional, and white-collar jobs, compared with 44 per cent among the foreign-born," with the consequence that "Chinese are no longer under-represented in professional and other white-collar occupations" (121-123).

The history I have briefly summarized forms the basis for one of the major representations of Asians in North America: the Model Minority discourse. First conceptualized during the 1960s in response to civil rights movements in the United States and Canada, it was meant to serve as an alternative discourse to the negative stereotypes that had painted Asian immigrants and their descendants as economic and cultural threats. Drawing upon historical narratives of perseverance in the face of racism - whether through capitalist entrepreneurship as exemplified by ethnic restaurants or laundries, or through the pursuit of higher education and upward social mobility (Wu 42-43) — the Model Minority discourse lauded Asian diasporic communities - first Japanese, then Chinese Canadians (Palumbo-Liu 171) ${ }^{1}$-as exemplars for other racial minorities to follow, their steady rise in academic and economic status attributed to Confucian ideals of diligence and deference to authority ( $\mathrm{Li} 61 ; \mathrm{Wu} 61)$. Combined with an immigration policy that ostensibly values educational and professional credentials over ethnic origin, and the increased wealth of Chinese within Asia, the commonly imagined Chinese Canadian subject today is one who has found success at school and in the workplace.

I, however, wish to consider a very different field in which Chinese Canadians have played a significant role in recent years: politics. Civic involvement has been a continual thread throughout Chinese Canadian history; even during Exclusion, ${ }^{2}$ immigrants and their children have constantly sought to assert themselves as citizens deserving of rights. This has expanded in recent years to more overt engagement with Canadian politics, as Chinese Canadians entered important positions within municipal, provincial, and federal government systems: for example, in 1987, due to the Liberal Party's endeavour to establish liaisons with ethnic minorities in Canada, Bob Wong was elected into Ontario's provincial government and accorded the

${ }^{1}$ Since its beginnings, the Model Minority discourse has expanded to include multiple Asian diasporas. However, the stereotype is still predominantly associated with immigrants from East Asia countries such as China, Japan, and South Korea (Wu 54). Other significant Asian immigrant communities - including Southeast Asian, South Asian, and Middle Eastern groups - are often omitted from this stereotype, or are perceived through a separate discursive lens by the mainstream EuroCanadian majority (Okihiro 3).

2 1923-1947: the period during which the Chinese Immigration Act, the legislation that largely barred Chinese immigration to Canada, was in effect. 
role of Minister of Energy (Huang and Jeffrey 85-86). ${ }^{3}$ In this paper, therefore, I will focus on two such individuals: Olivia Chow, who served both as a Toronto city councillor and a Member of Parliament for the New Democratic Party (NDP); and Adrienne Clarkson, who acted as Canada's Governor General in the early 2000s. Not only have both Chow and Clarkson become household names for many Chinese Canadians, but their achievements in office are particularly accessible to the public due to the memoirs they published recording their experiences: My Journey (2014) and Heart Matters (2006) respectively.

It is important to understand these two memoirs in their broader context in order to ascertain what I have found distinctive about them. According to Lien Chao, Chinese Canadian writing first appeared in Canada's literary canon as a distinctive genre in the 1970s (x), as authors and community members sought to claim ownership over their own histories and narratives amidst a growing market for minority arts and literature during the "human rights revolution" of the latter half of the 20th century (Chao 15; Kymlicka 35). Beginning with anthologies such as Inalienable Rice (1979) and Many-Mouthed Birds (1991), Chinese Canadian literature expanded to include novels, such as Wayson Choy's The Jade Peony (1995); anthologized transcriptions of oral histories, such as Chinese Canadians: Voices from a Community (1992) and Jin Guo: Voices of Chinese Canadian Women (1992); and biographies and memoirs, such as Wayson Choy's childhood reminisces in Paper Shadows (2000) and Denise Chong's multi-generational family account, The Concubine's Children (1994). Memoirs in particular figure prominently in the Chinese Canadian literary sphere from the 1990s onward, as part of a widespread increase in memoir writing and publication: the "memoir boom" during which "[works] by people who were not celebrities or political figures began to sell in large numbers" (Rak 9).

This conceptualization of the "memoir boom", then, places Chow and Clarkson's memoirs in a rather complicated light. Although both books are published as memoirs, and their titles - My Journey and Heart Matters - suggest an emphasis on narratives of personal growth and convey a feeling of intimacy between the author and the reader, they are, in fact, political memoirs: Chow and Clarkson both place greater emphasis on their careers within Canada's parliamentary system than on personal or emotional experiences (Gillis). This is perhaps due to a rightful concern for the ways in which minority life writing can easily slip into autoethnographic depictions of racialized minorities marketed primarily to satisfy the cultural voyeurism of the mainstream Euro-Canadian culture (Lai 58). For instance, despite her coining of the term "memoir boom", Rak warns that the increased marketability of memoirs by women and people of colour is as much a product of "Orientalist interest in the East" as it is of "liberal democratic empathy [and] activism" (132).

3 This work, Chinese Canadians: Voices from a Community, contains interviews with 23 prominent Chinese Canadians in a broad range of different fields and backgrounds. While its focus on key public figures means that it is not an accurate sample of the Chinese Canadian community at the time of its publication in 1992, it does serve as an example of the larger market appeal of success-driven narratives in a multicultural Canadian society. 
Similarly, in her criticisms of Canada's mainstream publishing industry and literary canon, Marlene Nourbese Philip notes:

Works by writers from cultures other than the dominant one often succeed in the publishing world of this culture, not only because they may be well-written, but also because they satisfy certain ideas already in existence in the dominant culture. (161)

Emphasis on their public selves as political figures, therefore, allows Chow and Clarkson an opportunity to be received by their readership on terms separate from their visually marked identities as Chinese Canadian women. Rather, in line with Rak's argument that memoir is "a writing of one's own life in relation to others, to events, or to the construction of some kind of public identity related to a popular issue of the day" (12), My Journey and Heart Matters explore their writers' public identities as Canadian politicians.

These public identities, therefore, will form the main point of comparative analysis in my study. In particular, although both Chow and Clarkson are Chinese Canadians, their writings reveal two vastly different perspectives, courtesy of their specific roles within Canada's political system. On the one hand, Olivia Chow has based her political career upon a series of attempts to garner equity and broader rights for Canada's myriad marginalized groups, including racial minorities. Conversely, Adrienne Clarkson not only downplays her own Chinese identity, but is a former Governor General: the representative of the British Crown within Canada's parliamentary system, and part of an institution still rooted in an outdated settler-colonial framework that continues to exalt English Canadians as the true Canadian subjects. However, despite their differing roles, both Chow and Clarkson are notable public figures within both Chinese and mainstream Canadian society; as members of a visible racialized minority, their presence, by default, interrogates the concept that there exists, to use Eva Mackey's phrase, an authentic "Canadian Canadian" that is "white, culturally unmarked, and unassimilated" (117-119). More specifically, Olivia Chow's social and political activism, rooted as it is in her experiences of marginalization, inspires Canadians to interrogate systemic forms of oppression and strive toward greater equity; while Adrienne Clarkson's visible presence as one of Canada's most internationally recognized public figures forces observers to reimagine the Canadian subject to include racialized minorities, regardless of her own personal attempts at assimilation.

\section{Activism and assimilation: A two-pronged fight for Chinese Canadian rights}

As public political figures, Chow and Clarkson are not alone; rather, they are part of a long history of Chinese Canadians' fight for recognition and citizenship rights in the face of racist and discriminatory immigration policy. The Canadian government, determined to discourage the arrival of undesirable immigrants - i.e., those 
not of Western European descent - first imposed a head tax on Chinese migrants in 1885 , followed by a widespread ban on Chinese immigration in 1923 . While formal restrictions on Chinese immigration were repealed in 1947, as part of Canada's commitment to the newly-established United Nations in the aftermath of the Second World War, it was only in 1967 that overt references to racial and/or ethnic origin were removed from immigration standards, thus officially mandating that Chinese applicants be received on equal footing with their European counterparts.

Over the course of this racial discrimination, many Chinese immigrants formed close-knit communities in Chinatowns. In these urban ethnic enclaves, they forged their own social and financial networks based upon such factors as clan ties or regional origins that fell outside mainstream Euro-Canadian control (Li 78). Moreover, a number of Chinese Canadians sought ways to circumvent the legal restrictions on immigration. Noting, for instance, that "diplomatic corps, children born in Canada to parents of Chinese race or descent, merchants, and students" were still granted entry into Canada (35), enterprising Chinese Canadians sold their children's identification papers to prospective immigrants in China (Djao 24); or, through the use of local bilingual interpreters, provided new arrivals with the "correct" responses to government officials (Mar 24). All of these methods allowed Chinese immigration to continue despite heavy restrictions, leading to the establishment of Chinatown communities and the birth of a second generation of Canadian-born Chinese.

These second-generation Chinese Canadians who came of age during the Exclusion Era (i.e. from 1923 to 1947) actively resisted the overt and systemic racism they faced. In part, this development was an unintended consequence of exclusionary immigration policy. Since regulations prevented a large influx of new Chinese immigrants, there was little incentive for Canadian-born Chinese to maintain emotional ties with their ancestral homeland; instead, this second generation was educated in Canada and socialized with their Euro-Canadian peers, and therefore perceived themselves as predominantly Canadian. Thus, Chinese Canadians began to fight for the status they believed was rightfully theirs: full citizenship and recognition in mainstream Canadian society (Mar 86-87). Examples of actions they took include participation in labour movements (Mar 83-84, 118), protests against racial segregation in schools (72-74), and even enlistment in the Canadian forces during the Second World War (128-129). As a result of these and other forms of social and political activism, Chinese Canadians played a significant role in the repeal of exclusionary immigration policy in 1947; although the federal government had its own additional agenda, this should not detract from the active role that Chinese Canadian communities played in their quest for citizenship.

In addition to political activism, a number of Chinese Canadians also sought belonging in mainstream Canadian society through affective performance. This approach entailed the appropriation of the positive traits that appeared in stereotyped depictions of Chinese immigrants: claims that can be traced back to a Royal 
Commission conducted by the Canadian government in 1885, which praised Chinese migrants as "most industrious, perfectly sober, very economical and ... law-abiding" (Report 94). Moreover, public emphasis was placed upon the Canadian-born second generation, who, due to their education and socialization among Euro-Canadian peers, were already emulating mainstream cultural norms. Thus, for example, in a 1924 sociological study conducted by the University of Chicago to examine the Chinese Canadian population's racial identity in comparison to both Whites and Blacks, the majority of volunteer informants were bilingual interpreters and second-generation youth, who were able to persuade researchers as to their desire and ability to assimilate into Euro-Canadian society (Mar 105). Naturally, such an act entailed a degree of self-censorship, as implied by the emphasis on performing positive stereotypical traits. In this, second-generation Chinese Canadians during the Exclusion Era were examples of Roland Sintos Coloma's concept of "ethno-nationalism", in which Asian Canadians "asserted and privileged one's Canadian-ness, or rightful belonging to Canada, albeit from the vantage point of a racialized minority, while simultaneously distancing oneself from and rejecting one's Asian-ness" (590). ${ }^{4}$ However, the end result was a reshaping and reimagining of the Chinese Canadian subject, in which they became not only viable - but desirable - Canadian citizens.

\section{Fighting for rights: Overt political activism in Olivia Chow's My Journey}

Throughout her professional and political career as described in My Journey, Chow, like those Chinese Canadians before her who resorted to overt civil protest, has been an advocate for those who have been systemically marginalized in Canadian society. Immigrating to Canada from Hong Kong in 1970 when she was thirteen years old, Chow was a member of one of the many Chinese families admitted under the official points system: her father had been an educational superintendent and her mother, a schoolteacher (Chow 21, 23-24). However, neither of her parents was able to continue in their chosen line of work; instead, like many racialized immigrants, they underwent a sharp depreciation in socio-economic status, struggling through a downward spiral of menial jobs and immense physical and mental stress (25-26).

According to the stereotypes portrayed in the Model Minority discourse, a racialized immigrant would seek higher education in order to achieve social mobility. However, Chow took a very different approach. Instead of looking out solely

${ }^{4}$ In contrast with the more common definition of ethno-nationalism, in which belonging in a nation-state is "defined in terms of assumed blood ties and ethnicity" (OHCHR), which would, in fact, exclude Asian immigrants and their descendants. 
for herself or her family, she committed herself to fighting for the rights of the underprivileged and the marginalized:

The isolation we felt as a family is something I have never forgotten ... My own experience within an immigrant family had stamped me, and when I became an elected official, I did all I could to change patterns and to find solutions. (27)

Thus, Chow's political career is marked throughout by an ability to look beyond her own immediate Chinese Canadian circle: for example, she began her activism by campaigning on behalf of Southeast Asian refugees displaced by the Vietnam War in the late 1970s (47). However, although she reminisces fondly about that campaign and its impact (47), Chow also reflects on the dangers of focusing only on one specific demographic at a time: "I remember one time being at the church for Sunday-afternoon fellowship and hymn singing. Through the window I spotted a homeless man, and I wondered: What's our response to his plight?" (48, emphasis in original). From this, there is evidence that even as an adolescent, Chow saw the importance of fighting against intersecting systems of racial, gender, and socio-economic barriers in order to advocate for all marginalized Canadians.

To that end, Chow is best known for her work as both a member of Toronto's municipal government and a Member of Parliament for the NDP, her involvement in which forms the central focus of My Journey. First, on a municipal level, as both a school trustee and a ward councillor, Chow advocated for reforms that would improve living conditions for Toronto's racialized minorities and urban poor. For example, she played a pivotal role in introducing heritage language education into school curriculums and eradicating streaming: the practice of placing students into either academic or technical secondary schools based on their grades at the elementary level, with academic schools providing the prerequisites needed for university (64-65). Both of these initiatives were a boon to racialized Torontonians. Heritage language education allowed the children of immigrant communities to learn their mother tongues alongside Canada's official languages, and encouraged students of all ethnicities to cultivate intercultural understanding through acquiring additional languages (64). Meanwhile, removing secondary school streaming would allow students, especially those from racialized and working-class communities lacking the resources needed for them to excel academically at the elementary level, to freely pursue their educational and career goals without constraint (64-65). These two motions, therefore, serve as evidence of Chow's commitment towards creating greater equity in the city of Toronto.

As for her career in Canada's federal government, Chow's strong sense of social justice drew her to the left-wing NDP. Their relationship was mutually beneficial: she saw the NDP as an institution passionate about helping the underprivileged in Canadian society, and the party recognized that having a Chinese member in its caucus would improve its relations with the Chinese Canadian community (52). After election as a federal MP, Chow continued to fight for the same social 
justice causes she had advocated as a Toronto councillor, but now on a much larger scale. One such initiative, which she discusses thoroughly in My Journey, is her attempt to create a national childcare programme that would allow both parents, especially mothers, to work to support their own families (126). This campaign shows Chow's deep awareness of intersections between gender and socio-economic status: Canada's capitalist economy was still biased towards men as primary breadwinners for their families, to the detriment of women. However, in her memoir, Chow also reveals the difficulties of fighting for social reforms in a time of economic instability in Canada: while early attempts did lead to $\$ 1$ billion in federal funding for childcare going to the provincial governments, it was seldom enforced, and few legislatures actually used the money as intended (130).

Fortunately, some of Chow's initiatives at the federal level did succeed despite opposition. For instance, she and her allies successfully demanded reparations from the government of Canada to the families of Chinese Canadians who had been subject to the head tax from a century ago (235-236). Although calls for a formal apology and monetary compensation had been ongoing since the 1980s, and the Canadian government readily acknowledged the role Chinese immigrants had played in the nation's early history, the official acknowledgement of the wrongs Canada had committed only came in 2006 (233). To be fair, formal reparations could only ever be a token gesture, a point Chow concedes in her memoir: "In a way, we knew that achieving redress would affect very few people directly - many head tax payers had died waiting for justice" (233). However, rather than the monetary compensation, Chow's passion and conviction in this case actually stemmed from the message an official apology would send: "[it] would and should affect all Canadians - not just Chinese Canadians - because it would be an affirmation of the right of all citizens to be treated equally under the law." (233). This statement, more than anything else in My Journey, best summarizes Chow's political stance: having achieved her own social, cultural, and political success, she now works to extend those same privileges and benefits to others, thus bringing about significant changes to how racialized and marginalized Canadians are taught and treated in the present day.

\section{Redefining Canadianness: Adrienne Clarkson's ethno-nationalism in Heart Matters}

Meanwhile, although she held one of Canada's highest positions as a former Governor General, Clarkson's contributions are markedly different from Chow's. In part, this is due to her specific post: as the Governor General, she was Canada's de facto head of state, meant to represent the role of the British Crown in Canada's parliamentary democracy. However, even more importantly, over the course of Heart Matters, it is her Canadian, not her Chinese, identity that Clarkson 
prioritizes. A Chinese refugee from Hong Kong who escaped to Canada during the Second World War (Clarkson 10), Clarkson grew up in a household that exhibited strong tendencies towards Coloma's ethno-nationalism. Her father, upon receiving news of the communist victory in China in 1949, severed the family's ties to their Chinese heritage (23), instead raising his children to believe that Canada was their permanent home and that emulating and performing Anglo-Canadian culture would be the best way to attain social acceptance.

Thus, while some vestigial remains of Chinese culture were retained in the household, Clarkson's parents urged her to assimilate. Styling themselves as educated British colonials from Hong Kong, they primarily socialized with their Euro-Canadian neighbours and encouraged their children to speak predominantly English (46); they also made conscious efforts to raise their daughter to have a strong will, in direct opposition to what they understood to be an intensely patriarchal Chinese tradition (47). Clarkson's parents even fostered in her a desire to become fluent in French, a dream she accomplished by living briefly in Paris as an adult (90). Clarkson, therefore, had a notably different upbringing from Chow: one which strongly paralleled the socialization and performed assimilation of the informants in the aforementioned 1924 study by the University of Chicago (Mar 105).

Like Chow, Clarkson is very clear throughout Heart Matters about the cause that she is most passionate about: the development of a Canadian culture centred on the achievements and civic actions of individual citizens instead of race and ethnicity. In fact, her commitment to this goal precedes her appointment as Governor General. In 1982, Clarkson, then a television programme host, was appointed to be Ontario's Agent General to Paris: a new post created to increase Anglophone Canadian liaisons with France (Clarkson 148). From her perspective, as described in Heart Matters, this new position as an Anglophone representative of Canada to France was proof that her decision to fully acculturate into mainstream Euro-Canadian society was, indeed, a success (148). However, it is also worth noting that Clarkson's appointment is contemporaneous with the shift in official Canadian policy towards "multiculturalism within a bilingual framework" (Canada 8545), in which the Canadian government committed both to granting equal footing to Anglo- and Franco-Canadians as Canada's founding cultures and expanding official recognition to all other ethnocultural groups. Thus, it is crucial to remember that Clarkson, although acting as the public face of Anglophone Canada to the French government in her capacity as Ontario's Agent General, is also a visible member of a racialized minority. Despite her self-identification as being solely an Anglophone Canadian (Clarkson 181), she is still visibly of Chinese descent and will be perceived as such both in Canada and abroad. Yet, despite all this, Clarkson maintains throughout Heart Matters that she was simply an individual whose credentials, including an ability to pass between both Anglophone and Francophone communities, allowed her to excel in a meritocratic liberal democracy, regardless of ethnicity (148). 
Clarkson, invested in her obligation to represent Canada without any reference to her ancestry, sought to promote what she perceived to be Canada's cultural interests in her time as Agent General. For instance, she derides in Heart Matters what she terms Canada's "colonial cringe": a tendency towards self-deprecation drawn from the belief that Canadians lacked culture in comparison with European nations like France (Clarkson 158-159). An example of this came in 1983, when a Canadian architect, Carlos Ott, won the contest for Paris' new opera house. Clarkson was frustrated at the Canadian embassy's tepid response to Ott's achievement, remarking that Canadian authorities "did not seem to react with the proper amount of pride, or have the ability to take advantage of such a marvellous coup" (158-59). Modesty in global relations has commonly been associated with Canada's international reputation for unobtrusive peacefulness, but Clarkson saw this as detrimental to the development of Canada's global image: "I've always been disturbed by how, as Canadians, we don't think very much of ourselves; we always believe that someone else might have the better idea" (161).

What Clarkson desires instead from Canada is a form of affective performance: becoming a stronger and prouder nation by encouraging citizens to both defend and promote each other's civic and cultural contributions. Thus, after her appointment as Governor General in 1999, Clarkson made strong efforts to generate the national pride that she felt Canadian society lacked. One way she worked towards this goal was through the use of a wide variety of awards for excellence: the Order of Canada, the Governor General's Award for literature, the Bravery and Caring Canadian Awards for acts of individual heroism, among others (205). Clarkson's plan was to redefine concepts of excellence and achievement for a Canadian society that had hitherto shied away from outward displays of pride in favour of a mythologized image of peace and harmony: "Many people feel that they have to best another in competition, but that is not the true mark of excellence. People concerned with excellence are always in competition with themselves, with what the sports world calls personal best" (205). In other words, Clarkson was not interested in rewarding those who were the "best" in any particular field; rather, she gave these awards to those whom she believed could act as role models for their fellow Canadians through acts of perseverance, diligence, good citizenship, and "selflessness and instinctive identification with the other" (205-206), such as that exhibited by Chow in My Journey. By drawing public attention to citizens who were passionate for social justice, Clarkson endeavoured to bring about inspirational change in Canadian society by encouraging others to do the same.

Indeed, it appears that Clarkson did even more than that. While her emphasis on a definition of Canadian culture and citizenship that focuses more on the achievements of individuals and communities, without consideration of their ethnic background, links her uncomfortably to an ethno-nationalism based upon assimilation into a Euro-Canadian mainstream, Clarkson's appointment as Canada's Governor General in 1999 might actually have the opposite effect. Throughout 
much of her life and career, rather than identifying herself as a hyphenated Chinese Canadian, Clarkson treats her Chinese birth as insignificant in comparison to her identity as a Canadian: an indication of a strong desire to dissociate herself from the stereotyped narrative of the token racialized politician and, instead, to be taken as a racially unmarked "Canadian Canadian" (Mackey 119). Yet, as Canada's first Governor General of Chinese descent, Clarkson also automatically called into question some of the conventional associations between race, citizenship, and power in Canada. She was, ultimately, a head of state and international representative that did not conform to that white "Canadian Canadian" standard for citizenship that had barred her predecessors from entering the country in the first place. Thus, by her presence alone, Clarkson has already changed the imagined Canadian subject into an image that must include racialized and marginalized faces and bodies - including, as it were, Chinese.

\section{Conclusion}

The life narratives of prominent Chinese Canadians such as Chow and Clarkson, as exemplified through their political memoirs My Journey and Heart Matters, show that a rise in social, cultural, and political influence has been of significant benefit not only for Chinese immigrants and their descendants, but for Canadians as a whole. Despite their high status and many accomplishments, Chow and Clarkson have not simply rested upon their own laurels. Instead, they have taken advantage of their influential positions in order to enact positive social changes: whether it is through activism and proposing new legislation to support Canada's marginalized and underprivileged, as in Chow's case; or through promoting an expanding vision of Canadian cultural identity both domestically and abroad, as it is with Clarkson. Both continue the legacy of Chinese Canadians' fight for citizenship and belonging in their own individual ways, and it is my hope that their stories will continue to inspire future generations of Canadians - Chinese or otherwise - who aspire to create a better Canada in the years to come.

\section{References}

Canada. Parliament. House of Commons. 1971. Debates, 28th Parliament, 3rd Session, Volume 8. 8545-8548, Appendix, 8580-8585.

Chao, L. 1997. Beyond Silence: Chinese Canadian Literature in English. Toronto: TSAR.

Chow, O. 2014. My Journey. Toronto: HarperCollins Canada.

Clarkson, A. 2006. Heart Matters: A Memoir. Toronto: Penguin.

Coloma, R. S. 2013. “'Too Asian?' On Racism, Paradox and Ethno-Nationalism.” Discourse: Studies in the Cultural Politics of Education 34.4. 579-598.

Djao, W. 2003. Being Chinese: Voices from the Diaspora. Tucson: U of Arizona P. 
Gillis, C. 2014, January. "Reviews: My Journey." Quill and Quire. Retrieved from https://quillandquire.com/review/my-journey/. 4 Feb. 2018.

Huang, E., and L. Jeffrey. 1992. Chinese Canadians: Voices from a Community. Vancouver: Douglas $\&$ McIntyre Ltd.

Kymlicka, W. 2010. "The Rise and Fall of Multiculturalism?: New Debates on Inclusion and Accommodation in Diverse Societies." In: Vertovec, S., and S. Wessendorf (eds.). The Multiculturalism Backlash: European Discourses, Policies and Practices. New York: Routledge, $32-49$.

Lai, L. 2014. Slanting I, Imagining We: Asian Canadian Literary Production in the 1980s and 1990s. Waterloo: Wilfrid Laurier UP.

Li, P. S. 1998. The Chinese in Canada. 2nd ed. Toronto: Oxford UP Canada.

Mar, L. R. 2010. Brokering Belonging: Chinese in Canada's Exclusion Era, 1885-1945. New York: Oxford UP.

Mackey, Eva. 2002. The House of Difference: Cultural Politics and National Identity in Canada. Toronto: U of Toronto P.

Nourbese Philip, M. 1992. Frontiers: Essays and Writings on Racism and Culture. Stratford, Ont.: Mercury P. Print.

OHCHR. 2018. "Ethno-Nationalism Denies Millions Their Citizenship Rights-Anti-Racism Expert." Retrieved from https://www.ohchr.org/EN/NewsEvents/Pages/EthnoNationalismDeniesTheirCitizenshipRights.aspx. 22 May 2019.

Okihiro, G. 1995. "Part One: Theory, Class and Place: Introduction.” In: Okihiro, G., et al. (eds.). Privileging Positions: The Sites of Asian American Studies. Pullman: Washington State UP, $1-9$.

Palumbo-Liu, D. 1999. Asian/American: Historical Crossings of a Racial Frontier. Stanford: Stanford UP.

Rak, J. 2013. Boom! Manufacturing Memoir for the Public Market. Waterloo: Wilfrid Laurier UP.

Report of the Royal Commission on Chinese Immigration: Report and Evidence. 1885. Ottawa: Printed by Order of the Commissioner.

Wu, F. H. 2002. Yellow: Race in America Beyond Black and White. New York: Basic. 